\title{
DESENHO ANIMADO, GÊNERO E SEXUALIDADES: "A HORA DA AVENTURA" E AS NARRATIVAS DISSIDENTES NA ESCOLA
}

- ANDRÉ LUIZ BERNARDO STORINO

Secretaria de Estado de Educação do Rio de Janeiro

IVAN AMARO

Universidade do Estado do Rio de Janeiro

RESUMO Neste artigo, refletimos sobre as possibilidades presentes no desenho animado "A Hora de Aventura", como artefato cultural potente para pensar as representações de gênero e sexualidade, a partir de narrativas de alunos e alunas do ensino médio de uma escola localizada na Baixada Fluminense. As narrativas produzidas pelos alunos e alunas esquadrinham suas percepções e a recepção do desenho como potência para a discussão de gênero e sexualidade na escola, configurando os significados que podem indicar subversões acerca dos conhecimentos que perpassam tais temáticas. As identidades de gênero e das orientações sexuais são tomadas em perspectiva não heterossexual, ao problematizarmos as representações de corpos e práticas que fogem à norma e desestabilizam as noções do suposto universo masculino e feminino, provocando novos saberes. Suas personagens fissuram as fronteiras e ensejam reconhecimento e identificação nas vivências e práticas das/os discentes.

Palavras-chave: Gênero. Desenho animado. Narrativas. Orientação sexual.

\section{ABSTRACT ANIMATED, GENDER AND SEXUALITIES: "ADVENTURE TIME" AND DISSIDENT NARRATIVES IN SCHOOL}

In this article, we reflect on the possibilities present in the cartoon "Adventure Time" as a powerful cultural artifact to think about the representations of gender and sexuality from narratives of students and high school students of a school located in the Baixada Fluminense. The narratives produced by the students evaluate their perceptions and the reception of the drawing as power for the discussion of gender and sexuality in the school, configuring the meanings that may indicate subversions about the knowledge that perpasses 
these themes. Gender identities and sexual orientations are taken in a non-heterosexual perspective by problematizing the representations of bodies and practices that escape the norm and destabilize the notions of the supposed masculine and feminine universe provoking new knowledge. Their characters fissure the borders and allow recognition and identification in the experiences and practices of the students.

Keywords: Gender. Cartoon. Narratives. Sexual orientation.

\section{RESUMEN DISEÑO ANIMADO, GÉNERO Y SEXUALIDADES: "LA HORA DE LA AVENTURA" Y LAS NARRATIVAS
DISSIDENTES EN LA ESCUELA}

En este artículo, reflexionamos sobre las posibilidades presentes en el dibujo animado "La Hora de Aventura" como artefacto cultural potente para pensar las representaciones de género y sexualidad a partir de narrativas de alumnos y alumnas de la enseñanza media de una escuela ubicada en la Baixada Fluminense. Las narraciones producidas por los alumnos y alumnas escudriñan sus percepciones y la recepción del diseño como potencia para la discusión de género y sexualidad en la escuela, configurando los significados que pueden indicar subversiones acerca de los conocimientos que atraviesan tales temáticas. Las identidades de género y de las orientaciones sexuales se toman en perspectiva no heterosexual al problematizar las representaciones de cuerpos y prácticas que huyen de la norma y desestabilizan las nociones del supuesto universo masculino y femenino provocando nuevos saberes. Sus personajes tiñan las fronteras y enseña reconocimiento e identificación en las vivencias y prácticas de los / las discentes.

Palabras clave: Género. Dibujo animado. Narrativas. Orientación sexual.

\section{Por que as temáticas de gênero e sexualidades devem ser tratadas}

\section{na escola?}

No momento em que produzimos este artigo, o país enfrenta a materialização de ataques à democracia e ao Estado de Direito, por meio de um golpe jurídico-político-midiático gestado desde as eleições de 2014 e que se consumou com o afastamento da Presidenta
Dilma Roussef, em 2016. Estarrecidos, vemos movimentos de completo desmonte dos direitos sociais, o retorno do Brasil ao mapa da fome, altas taxas de desemprego, aprovação da lei de terceirização e da reforma trabalhista, bem como a mobilização do Congres- 
so Nacional para a aprovação da reforma da previdência.

Este cenário é agravado pelo contexto de embates, tensões, disputas e conflitos que cercam os direitos de indígenas, quilombolas, negros e negras, mulheres, lésbicas, gays, bissexuais, transexuais, travestis e transgêneros. Temos acompanhado, especificamente, as disputas de narrativas que envolvem as questões de gênero e de diversidade sexual. Os movimentos políticos, religiosos e conservadores, vêm intensificando sua ofensiva contrária à inserção dessas temáticas no âmbito do currículo escolar e das práticas pedagógicas, na escola, desde o início da década de 2000, e têm compactuado, sistematicamente, com as reformas de ampla caça aos direitos daqueles/daquelas que não se encaixam no padrão da heterossexualidade estrutural. Nesta arena, no campo da educação, duas narrativas ganham destaque: uma que trata da ampliação de espaços para a discussão de gênero, em todas as suas manifestações, no interior das escolas, no combate às violências, aos preconceitos e às discriminações, e outra que sustenta sua contrariedade na defesa da moral, da família e dos "bons costumes". Mesmo não sendo o foco principal de nosso artigo, cabe aqui elucidar como estas narrativas vêm se confrontando e como temos buscado espaços de fuga, brechas, fissuras, para intensificar e promover a discussão de gênero e de sexualidades, no cotidiano escolar, pois, ao focalizarmos estas temáticas, estaremos contribuindo para a formação de um sujeito mais solidário, mais respeitoso, menos preconceituoso e mais afeito a relações saudáveis de reconhecimento do outro.

A primeira narrativa trata, de modo bastante amplo, de alguns movimentos que desencadearam a ira de oposição, principalmente dos discursos religiosos conservadores. Em 2004, foi aprovado o Programa de Combate à
Violência e à Discriminação contra LGBT e de Promoção da Cidadania Homossexual - Brasil Sem Homofobia. Como desdobramento, a Secretaria de Educação Continuada, Alfabetização e Diversidade (SECADI/MEC) apoiou o "Projeto Escola Sem Homofobia". O projeto foi planejado e executado em parceria com a Global Alliance for LGBT Education (GALE) e as ONG's (Organizações Não Governamentais) Pathfinder do Brasil, ECOS (Comunicação em Sexualidade), Reprolatina (Soluções Inovadoras em Saúde Sexual) e a ABLGBT (Associação Brasileira de Lésbicas, Gays, Bissexuais, Transexuais e Travestis). Seu objetivo vislumbrava a contribuição para implementar e efetivar ações promotoras de espaços sociais e políticos que favorecessem a garantia dos direitos humanos e a respeitabilidade das orientações sexuais e de gênero, no interior das escolas brasileiras. A colaboração dessa rede se traduziu em subsídios para incorporar e institucionalizar ações de enfrentamento à lgbtfobia na escola. Além de apoiar, financeiramente, 15 projetos de formação de profissionais da educação para a cidadania e a diversidade sexual, com a participação de secretarias de educação, de universidades e do movimento de lésbicas, gays, bissexuais, transexuais, travestis e transgêneros, o MEC também constituiu um Grupo de Trabalho (GT) para pensar e elaborar um plano de ações voltado à promoção da diversidade sexual e ao combate das várias formas de violação dos direitos humanos de gays, lésbicas, transgêneros e bissexuais. O GT era composto por representantes de todas as secretarias do MEC, do Instituto de Pesquisa Anísio Teixeira (Inep/MEC) e da Coordenação de Aperfeiçoamento de Pessoal de Nível Superior (Capes/MEC), além de diversas entidades do movimento social LGBT.

A partir daí, dentre diversas ações (BRASIL, 2007), estabeleceram-se estratégias para trabalhar as temáticas de gênero e sexualidades, 
no âmbito da escola, focalizando objetivamente conteúdos voltados para a homo/lesbo/transexualidade, tendo em vista visibilizar outras formas de vivência das sexualidades. Neste contexto, surge a proposta de criação de um kit de material educativo, abordando aspectos da homo/lesbo/transfobia na escola, direcionado para gestores/as, educadores/ as e estudantes. A ECOS ficou responsável pela criação do material educativo e da metodologia/conteúdo de formação, e pela preparação da equipe de formadores/as.

Este foi o estopim para que as forças conservadoras colocassem em tela suas narrativas. A narrativa dessas forças apoiou-se em falas enviesadas e de grande impacto na mídia, por diversos parlamentares que chegaram a apelidá-lo de "kit gay". o conteúdo dessa narrativa, de forma bastante superficial e simplista, indicava que o MEC estaria incentivando a formação de lésbicas, gays, bissexuais e transexuais, desde a infância, e que isto era um atentado contra a família. Dessa forma, a pressão dessa bancada conservadora, aliada à bancada religiosa, provocou o veto presidencial ao material educativo. No processo de elaboração do Plano Nacional de Educação (PNE, 2014-2024), as bancadas conservadoras reforçaram o intento desse controle sobre a educação. Impediram que qualquer termo relacionado a gênero, sexualidade ou orientação sexual fosse retirado do documento final. Como ataque mais incisivo dessas forças, tramita o Projeto de Lei no 867, de 2015, no Congresso Nacional, que inclui, na LDB 9394/96, o "Programa Escola Sem Partido", que tem entre um de seus eixos a contraposição ao que denominam como "ideologia de gênero", ou seja, aponta caráter proibitivo para que as discussões de gênero e sexualidades aconteçam nas escolas.

Tais ataques, interdições, censura e regulação ao caráter democrático da escola impõem a nós, educadores/as, pesquisadores/as as- sumirmos a resistência e a defesa da produção de conhecimentos que se contraponham aos discursos do senso comum ou enviesados política e teoricamente. Este artigo apresenta alguns achados de estudo finalizado, com o título "Gênero, beleza e corpo nos desenhos animados: recepção e percepções de alunas e alunos do ensino médio de uma escola pública do Rio de Janeiro", vinculado ao NuDES (Núcleo de Estudos e Pesquisas Diferenças, Gênero, Educação e Sexualidades), da UERJ (Universidade do Estado do Rio de Janeiro) e certificado pelo CNPq (Conselho Nacional de Desenvolvimento Científico e Tecnológico), e que compõe uma pesquisa mais ampla, intitulada "Educação, diferença, gênero e sexualidades: potencialidades de um currículo queer e decolonial nos cotidianos escolares de periferias urbanas".

Diante de todo o cenário em que estamos inseridos, parece haver uma teimosa tentativa cotidiana de organizar os espaços pelos corpos ou os corpos pelos espaços, cuja fronteira não se pode claramente delimitar, e onde cada qual habita ou é habitado. A maior visibilidade e expressão de movimentos sexuais libertários provoca manifestações acirradas de setores conservadores pelo controle dos corpos.

À medida que movimentos que englobam diversas identidades (lésbicas, gays, bissexuais, transexuais, travestis, transgêneros, intersexuais, queers) ganham projeção e maior visibilidade nas lutas por direitos e pela desestabilização da ordem heterossexual, os grupos conservadores se organizam num movimento contrário de combate a estes movimentos considerando-os "perigosos", desestabilizadores da ordem familiar, subversivos e ameaçadores, na perspectiva de perverter conceitos, valores e modos de viver padrão (LOURO, 2013). Parece haver a concepção, como um consenso

1 Programa Prociência - UERJ, financiado pela FAPERJ (Fundação de Amparo à Pesquisa do Estado do Rio de Janeiro). 
naturalizado desses grupos, de que se pode, de alguma forma ordenar, controlar, interditar e organizar nossas vidas, e fazê-lo a partir de modelos, cuja ideia de inteireza nos conduz à vacilante sensação de que exista uma natureza, uma essência, que bem controlada, deve (e pode) ser alcançada. Nessa visão, fixar-se é quase uma lei. Fixação esta que algumas teorias se responsabilizam em construir e manter. As tecnologias empregadas pretendem controlar, disciplinar, dominar os corpos e suas atividades; portanto, regular e controlar os corpos individuais e coletivos compõe o escopo das determinações de poder que estão envolvidas na sociedade.

No entanto, nossos corpos teimam em desorganizar, em desestabelecer o estabelecido, em bagunçar o organizado, em subverter o que está padronizado. Pensar em caminhos de (des)construção, seja das representações dos corpos, em sua configuração estática, foi o que nos encaminhou pelo universo das imagens, das audiovisualidades, mais especificamente, nos jogou no universo dos desenhos animados. Neste sentido, compreendemos que, ao focalizarmos os recursos das imagens, é possivel constituirmos movimentos para produzir significados, conhecimentos e sentimentos.

O objetivo foi investigar as constituições dos aspectos relativos ao gênero e à sexualidade, compreendendo as narrativas construídas por jovens do ensino médio, a partir das provocações realizadas pelos significados inscritos na recepção dessas imagens. Além de fontes de entretenimento, as animações possuem potência para veicular informação, provocar a formação e as aprendizagens não inscritas no currículo e nas práticas escolares (GIROUX, 1995).

O processo de subjetivação construído pelos desenhos é bem exemplificado na infância, em que os modelos de feminilidade são representados por princesas e os modelos de masculinidade são representados pelos super -heróis. Eles descrevem e induzem, ao mesmo tempo em que prescrevem, modos de ser, de se comportar e de agir. Sua força de persuasão está nas representações e se intensifica pela repetição como um dos mecanismos que merece atenção, pois não há uma "zona confortável e ideologicamente neutra" (GIROUX, 1995, p. 63). Para Giroux (1995), as representações dos desenhos animados, de um suposto universo fantasioso, despretensioso, ingênuo e voltado ao entretenimento, não podem ser desvinculadas das condições produtoras de subjetividades, intimamente ligadas às premissas econômicas. Ao analisar filmes animados produzidos pelos estúdios Disney, Giroux (1995) percebe que seu alcance ultrapassa os limites da imaginação e da fantasia.

Antes de me tornar um observador dessa forma de cultura infantil, eu aceitava o geralmente inquestionável pressuposto de que os filmes animados estimulam a imaginação e a fantasia, reproduzem uma aura de inocência e saudável aventura e, em geral, são 'bons' para as crianças. Em outras palavras, esses filmes pareciam ser veículos de divertimento, uma fonte altamente respeitada e buscada de prazer e alegria pelas crianças. Entretanto, num período muito curto, tornou-se claro para mim que a relevância desses filmes ultrapassava as fronteiras do divertimento. É desnecessário dizer que a importância dos filmes animados opera em muitos registros, mas um dos mais persuasivos é o papel que eles exercem como novas 'máquinas de ensinar'. (GIROUX, 1995, p. 51)

Os modelos figurados nas representações sociais do que seja homem ou mulher, menina ou menino, branco ou negro, dentre tantas outras binaridades, são construções políticas, históricas, sociais e culturais. Estas construções definem identidades rígidas e não resultantes de embates políticos, enclausurando corpos em modelos fixos e rígidos, negando sua corporeidade fluída, aberta e inacabada. 
É relevante que nos debrucemos sobre as potencialidades dos desenhos animados, entendidos como artefatos culturais e enquanto processos imagéticos que captam a atenção de crianças, jovens e adultos, interferindo em suas subjetividades. Atualmente, há um número considerável de produções animadas que focalizam as questões de gênero, colocando -as em tensão.

O desenho "Peppa Pig", veiculado em canais abertos e fechados foi chamado de feminista por alguns políticos conservadores. No desenho, o arranjo familiar constitui-se por papéis sexuais que não encontram eco nas normalizações heterossexistas. A família da porquinha define as tarefas domésticas em uma lógica mais flexivel do que a hierarquia heterossexual vigente, em que mulheres cuidam dos afazeres de casa e homens trabalham fora para prover o sustento. No desenho, a mãe trabalha no computador e o papai prepara o jantar. Isso representa um quadro de alteração dos papéis sexuais e de gênero no cotidiano das pessoas. Tal mudança dialoga diretamente com a realidade de diversas famílias em que as mulheres, cada vez mais, trabalham fora de casa e assumem o papel de dirigentes familiares.

O desenho "Padrinhos mágicos" apresenta um conjunto de discussões bem complexas sobre as questões de gênero, em especial, em relação às masculinidades. Num determinado episódio, o pai do Timmy, protagonista do desenho, pergunta: “onde, nesta sociedade de um só lado, está escrito que um homem não pode ser bonito?" Em outro episódio, intitulado "Meninos e Meninas", 2 Timmy transforma-se em uma menina para descobrir qual é o presente de aniversário perfeito para Trixie. No episódio, são colocados em questão as diferenças sexuais. Papéis são trocados e Timmy encontra Trixie no shopping, disfarçada de

2 Disponivel em: <https://www.youtube.com/watch?$\mathrm{v}=98 \mathrm{k} 9 \mathrm{HnAF} 2 \mathrm{XM}>$. Acesso em: 15 abr. 2017. "menino". Ele descobre que ela gosta de brinquedos de "meninos". A partir daí, a narrativa vai se constituindo pelo atravessamento de atividades que, histórica e culturalmente, foram definidos como masculinos ou femininos, e que são colocados em processo de desconstrução.

Assim, os desenhos animados podem se constituir em recurso potencial para apontar as ambiguidades das representações que envolvem as questões de gênero. É com esta perspectiva que pautamos nossas investigações acerca do gênero e das sexualidades, defendendo sua inserção/ampliação no espaço dos currículos e das práticas pedagógicas escolares.

A investigação pretendeu analisar a (des) construção de identidades de gênero e dos referenciais de beleza inscritos nos seguintes desenhos animados: A Hora da Aventura, 0 Clube das Winx e As Três Espiãs Demais. Na próxima seção, apresentaremos os percursos seguidos para chegarmos a estes três desenhos e, para efeito desse artigo, descreveremos as sessões de exibição e as análises empreendidas, especificamente sobre o desenho "A Hora da Aventura". Na seção seguinte, focalizaremos a recepção e as percepções das alunas, a partir dos Grupos de Exibição, analisando como ressignificam as narrativas dos episódios vistos, a partir das perspectivas de gênero, bem como rearticulam suas próprias narrativas. Por fim, indicamos algumas potências do aparato dos desenhos animados para promover a discussão de gênero e sexualidades, no âmbito da escola, e como forma de combater a violência misógina e lgbtfóbica.

\section{Iniciando nossa aventura: trilhas, caminhos e orientações...}

A seleção dos desenhos indicados anteriormente deu-se, inicialmente, pela aplicação de 
um questionário ${ }^{3}$ que buscava identificar se adolescentes do ensino fundamental (segundo segmento) e do ensino médio, em uma escola pública de Duque de Caxias/RJ, os assistiam e em qual frequência. Foram aplicados e respondidos 36 questionários. Desse universo, vinte e uma alunas e quinze alunos responderam.

No ensino fundamental, foram entrevistadas quatro alunas, duas do oitavo ano e duas do nono, e quatro alunos, um do oitavo e três do nono. Do ensino médio, participaram vinte e oito alunos, no total, sendo quatorze meninas e dez meninos do primeiro ano e três meninas e um menino do terceiro ano, cuja faixa etária era de 13 a 18 anos.

A primeira informação que nos chegou foi a de que todas/os já haviam assistido ou ainda assistem a diversos desenhos animados. Outra informação importante foi a de que $70 \%$ dos respondentes assistem aos desenhos pelos canais fechados de televisão (SKY, OI TV, CLARO TV), mesmo que também os vejam em canais abertos. Todos/as afirmaram possuir acesso à internet, doze afirmaram que também utilizam o Netflix para assistir aos desenhos, enquanto um assiste pelo YouTube.

Dentre os respondentes, 12 alunos/as afirmaram que assistem aos desenhos pelo menos uma vez por semana, oito assistem duas vezes por semana, sete assistem três vezes por semana e nove assistem diariamente, o que indica que a frequência de audiência dos desenhos é bastante significativa. Em seguida, os/ as alunos/as foram provocados/as a registrar quais desenhos estavam assistindo.

Então, a que estavam assistindo estes adolescentes e jovens?

"A Hora da Aventura" foi um dos desenhos mais assistidos. Foram 13 alunas e quatro alu-

3 Foi encaminhado aos pais, mães e/ou responsáveis, para os menores de 18 anos, o Termo de Consentimento Livre e Esclarecido, para a participação na pesquisa. Foram assinados os termos de quem respondeu aos questionários e participou dos grupos de exibição. nos. Dentre os demais, ${ }^{4}$ destacamos, mesmo que não fossem os mais assistidos, conforme resultados do questionário, estão "O Clube da Winx, visto por três meninas e três meninos, e “As Três Espiãs Demais", assistido por 10 meninas, mas nenhum menino. Estes três desenhos possibilitaram a discussão das representações estéticas e favoreceram pensar as metanarrativas sobre gênero, sexualidade, identidades de gênero e sexuais, bem como os atributos acerca de corporeidades e beleza.

Em seguida, foram constituídos Grupos ${ }^{5}$ de Exibição, organizados a partir dos seguintes critérios, respectivamente: a) primeiramente, alunos e alunas que assistem "A Hora da Aventura"; b) alunos e alunas que indicaram que assistem ou assistiram aos desenhos " $O$ Clube da Winx" e/ou "As Três Espiãs Demais". As exibições aconteceram em dois momentos, no turno da manhã, com a participação de seis meninas (Jean Grey, Tempestade, Vampira, Ororo, Lince Negra, Mística) e um menino (Grush).

Para selecionar os episódios que seriam exibidos, foram considerados aspectos pertinentes à temática, com elementos implícitos de marcadores de identidades de gênero, de sexualidade e marcadores explícitos (e também implícitos) em relação à beleza, uma vez que:

Habitamos uma cultura fotocêntrica, auditiva e televisual na qual a proliferação de imagens e sons eletronicamente produzidos serve como uma forma de catecismo da mídia, uma pedagogia perpétua, através da qual os indivíduos ritualmente codificam e avaliam os envolvimentos que fazem nos vários contextos discursivos da vida. (GIROUX, MCLAREN, 1995, p. 144)

No primeiro dia, foram assistidos dois episódios de "A Hora da Aventura": "Mamãe disse"

4 Bob Esponja, Tom e Jerry e Scooby-Doo foram citados entre os desenhos mais assistidos, contudo, para a temática deste trabalho, abrimos mão por não explorarem, em suas representações, corpos humanos.

5 Não houve participação das alunas e alunos do fundamental na composição dos grupos. Participaram apenas respondendo ao questionário. 
e "O que faltava". Tais episódios, com a duração de 11 minutos, explicitam os marcadores de gênero, de sexualidade e de beleza, problematizando convenções, normas e padronizações. Esta primeira sessão teve a duração de 1 hora e 50 minutos, com um intervalo de 10 minutos, solicitado pelos participantes. No retorno do intervalo, voltaram apenas as meninas.

Inicialmente, foram exibidos os dois episódios e, na sequência, provocamos as discussões com indagações acerca das representações de identidades de gênero e sexuais, estabelecendo vínculos com as representações dos corpos e de beleza, tendo em vista questões, tais como: que questões as narrativas dos episódios provocaram? Quais as representações do feminino e do masculino que são constituídas a partir das imagens? Quais as imagens fisicas predominantes e "aceitáveis" para o homem e para a mulher nos desenhos? O que pode ou não fazer uma menina e um menino? Quais e como são os locais de poder atribuídos ao feminino e ao masculino? De que forma estão atribuídas ao feminino e ao masculino as noções de bom e mau? Qual transgressão é realizada, seja pela mulher ou homem, dos papéis "naturalizados"? Quais os atributos preponderantes para se considerar a beleza? Como a beleza é caracterizada nas personagens feminina e masculina? Como se relacionam (a identidade de) gênero com a representação da beleza corporal e seus traços?

"A Hora da Aventura" nos coloca frente à vacilante inteireza do ser e à aventura do devir, cujas certezas despedaçam-se, ao mesmo tempo em que tentamos reorganizá-las. o que pode ser corroborado pela fala de uma aluna que tenta explicar o que o desenho faz em sua cabeça: "este desenho dá uma bugada ${ }^{6}$ na nossa cabeça".

6 Gíria utilizada por jovens para indicar uma pane, confusão. Tem origem no termo bug, em inglês, que indica, comumente, um erro que acontece no sistema operacional ou em programas de computador.

\section{Mas que aventura este desenho} propõe? Narrativas dissidentes e os (des)enlaces de gênero

"A Hora da Aventura", criada por Pendleton Ward, é uma série de desenho animado exibida no canal de TV Cartoon Network, que assim a descreve, em suas chamadas, como uma série animada que traz dois heróis um tanto incomuns: Finn \& Jack, amigos que chegam à mítica Terra do Ooo e encontram seus habitantes coloridos. O desenho é classificado para uma faixa etária de doze (12) anos de idade, mas tem chamado a atenção de adolescentes, adultos e pesquisadores ${ }^{7}$ do campo de gênero, por retratar, por meio de suas metáforas, as transgressões de identidades de gênero e sexuais.

Finn e Jack são as personagens principais que, em suas diversas aventuras, estão sempre problematizando questões de cunho existencial, de natureza filosófica, moral, ética, amorosa, identitária, dentre outras. Finn, o único humano, contracena com uma diversidade de figuras personificadas, animadas e híbridas. A série já encontra-se em sua 7a temporada. Cada temporada conta com, aproximadamente, 30 episódios. Não há repetição, seja na narração, nas histórias, nos personagens ou cenários.

Há personagens que têm uma maior visibilidade, o que nos leva a afirmar a existência de uma estruturação narrativa bastante comum: enredo, personagens protagonistas, persona-

7 Na estreia, em 2010, nos Estados Unidos, o episódio "Pânico na festa do pijama", alcançou 2,5 milhões de espectadores. A audiência aumentou sensivelmente, atingindo crianças e adolescentes de forma significativa. Segundo dados da própria Cartoon Network, houve um aumento considerável. Por exemplo, o episódio foi visto por 1,661 milhões de crianças entre $2 \mathrm{e}$ 11 anos (um aumento de 110\%), enquanto na faixa de 9 a 14 anos, 837.000 crianças/adolescentes viram o desenho, o que indica um aumento de $239 \%$. Conforme o sistema de medição de audiência Nielsen Ratings, a série é a primeira entre crianças/adolescentes de 2 a 14 anos. Ver: Ramos e Fernandes (2016) e Silva (2016). 
gens secundários etc. Há um núcleo mais fixo que está presente em grande parte dos episódios e que movimenta a trama. Este núcleo é composto pela Princesa Jujuba, uma princesa que governava o Reino Doce e que vai despertar em Finn uma admiração amorosa por determinado tempo; Marceline, uma vampira de mais ou menos 1000 anos, mas com uma aparência de menina de 18 a 20 anos e que se torna uma das melhores amigas de Finn e Jack; Lady íris, é uma "iriscórnio", 8 com poderes de mutação, companheira de Jack e mãe de suas filhas e filhos, como também uma amiga da Princesa Jujuba; Rei Gelado, governante do Reino Gelado, que retira seu poder da sua coroa, que é apresentada como causadora de sua "insanidade", cuja obsessão está em sequestrar as princesas e obrigá-las a se casarem com ele; ação que acaba por ser frustrada, visto que Finn e Jack estão sempre em seu caminho. A figura a seguir mostra estas personagens.

Figura 1: Finn, Rei Gelado, Lady Iris, Jack Princesa Jujuba e Marceline.

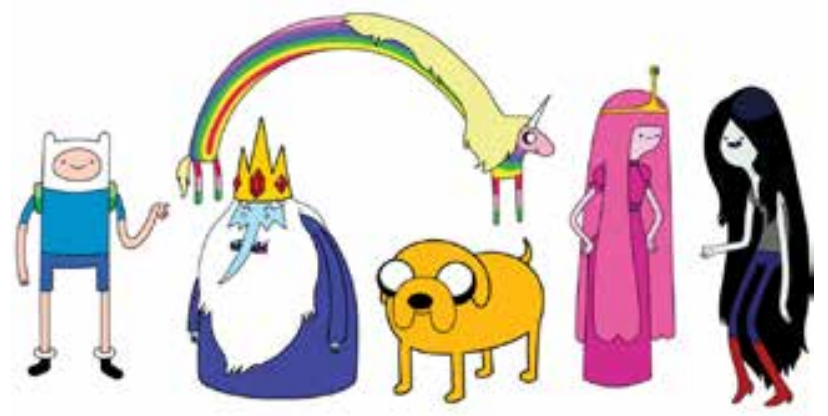

No episódio "O que faltava", uma criatura passa roubando os pertences mais caros a cada uma/um e os esconde atrás de uma porta que só se abre ao som da canção de uma verdadeira banda. Princesa Jujuba e a Vampira Marceline travam uma disputa que nos conduz

8 Hibridismo entre arco-íris/unicórnio que vive em paz na Terra de 0 oo e na Dimensão Cristal. Possui habilidade de voar por interceptar a luz solar e "dançar através dela", podendo mudar a cor de qualquer objeto por um raio do chifre. à sensação de que ambas são um casal em um relacionamento lésbico.

Enquanto em "Mamãe disse", há uma obsessão do Rei da Terra de Ooo pela captura de um cogumelo voador; neste episódio, o rei aparece nos trajes da Princesa Jujuba e exige que o chamem de "My Lady". Enquanto Finn e Jack se aventuram para capturar o cogumelo voador, encontram Canyon que vai ajudá-los nesta missão que termina em fracasso. 0 desenho vem fomentando as possibilidades de representar as fragilidades das concepções binárias. Traz construções de narrativas e representações de personagens em que um olhar, desatento e apressado, classificaria como não possuidor de sentido lógico, com objetivo bastante intrincado, confuso, quando não, "muito louco", conforme a fala de Jean Grey, no grupo de exibição.

Conforme fomos conversando e problematizando alguns conceitos, a partir dos episódios assistidos, pôde-se reconhecer a existência de premissas que sustentam a representação do gênero e da sexualidade, segundo postulados políticos resultantes de processos culturais e históricos (BUTLER, 2015; LOURO, 2013). Isto se concretiza na constituição dos seres que povoam os episódios, o que a aluna Vampira vai chamar de "essas mensagens subliminares", para descrever as mensagens latentes que 0 desenho propõe.

As razões dadas para assistir ao desenho parecem inserir-se no escopo do divertimento, do entretenimento, indicando um olhar mais ingênuo e menos detido às imagens que são veiculados na tela. Ao serem provocadas, as alunas começam a expor as razões que estão ligadas aos temas que thes interessam e que acabam por delinear suas potencialidades para a construção de aprendizagens sobre representações, gênero e sexualidades, em enlaces não binários. Isso nos permite sustentar que as narrativas desenvolvidas, diferente- 
mente dos muitos outros desenhos, deixam intrínsecas as possibilidades, quando não da desconstrução, da ressignificação de modelos fixos. 0 que se depreende do diálogo, ${ }^{9}$ a seguir:

Vampira: Gosto de assistir porque faz bem, é bem divertido e tal. Para passar o tempo também.

Jean Grey: Eu acho que aborda temas legais assim.

Tempestade: Eles disfarçam em forma de desenho.

Jean Grey: Em forma de animação.

Pesquisador: Quais temas?

Jean Grey: A princesa caroço é basicamente a representação de uma pessoa trans, que parece ser uma coisa, mas se apresenta como outra.

Tempestade: Igual a princesa rei.

Jean Grey: A princesa rei, que talvez seja um cara que quer ser uma princesa, mas tem corpo de um homem.

Aqui, as representações que aparecem no desenho diferem daquelas relacionadas ao lugar comum das concepções dualistas do ser masculino e feminino e, ao que parece, são recebidas e percebidas por alunos/as com naturalidade, o que vem ao encontro da abertura que o grupo demonstrou em relação aos assuntos que julgava não ser possivel conversar abertamente em casa, com a família, e nem na escola, a saber: gênero e sexualidade (LOURO, 2014; GALLO, 2014; GIROUX, 1995). Ademais, reforça a ideia de "máquina de ensinar" a que se refere Giroux (1995), que se utiliza de aparato tecnológico cada vez mais moderno e que conjuga autoridade cultural com entretenimento; este é revestido do aspecto pueril para formar e informar ideias e valores acerca das identidades e diferenças, tais como "sistemas de representações" (HALL, 2016).

De certa forma, a existência desses temas presentes no desenho, o modo como aborda e transmite as temáticas, e a identificação pelas alunas parece sugerir certa assimilação, entre

9 Os diálogos são apresentados na mesma ordem em que foram proferidos. o que o desenho discute e o que a vida propõe, que, neste caso, reflete algumas experiências seja em relação às identidades de gênero, seja em relação à sexualidade, ainda que, direta ou indiretamente, ocorridas consigo mesmas/os ou com outras/os, conforme se percebeu nas informações pessoais fornecidas, ${ }^{10}$ quando falaram de suas orientações sexuais e suas questões identitárias, que são atravessadas pelos "sistemas de representações" (HALL, 2016, p. 42). Sistemas estes que são construídos a partir das convenções sociais de cada cultura.

0 sistema de representação, em que o sentido não é algo fixo na natureza, ou no objeto, e que parece que jamais será fixado em absoluto é o que torna "A Hora da Aventura" um desenho animado significativo e estimulante das discussões de temas próximos às vivências de alunos/as. Jean Grey aponta isso de forma muito clara acerca da Princesa Caroço, ao considerá-la a representação de uma "pessoa trans"11 ou seja, "parece ser uma coisa e é outra".

Sua figura foge da "norma" e se afasta do centro normativo (LOURO, 2013), cuja regulação dos gestos e falas, as imposições do modo de ser e agir são sempre bem policiadas a partir da identidade masculina, branca, heterossexual, que é resultado dos marcadores que foram estabelecidos em determinado meio, cuja aceitação é mais ou menos permitida, a depender das diferenças incorporadas (BHABHA, 1998; BRAH, 2006). A Princesa Caroço é uma das personagens responsáveis por introduzir a temática das identidades de gênero "trans". Sua aparência é representada por uma nuvem flutuante e não segue a figura de um

10 Escolhemos abordar as questões de natureza mais íntima, nas conversas individuais, uma vez que no grupo de exibições poderia causar constrangimentos para os/as alunos/as. Desta forma, as/os demais participantes só revelaram suas orientações sexuais quando indagados nestas conversas, exceto Lince Negra, que havia dito abertamente perante o Grupo de Exibição.

11 Termo informal largamente utilizado para representar transexual. 
corpo humano. No entanto, sua voz "grossa" e seu modo de falar sugerem, como dito pela aluna Jean Grey, que ela tem uma identidade de gênero diferente, marcada pela voz e pelos trejeitos considerados masculinos.

Os elementos que a compõem desestabilizam a noção de princesa até então construída e mantida pelos desenhos animados, princi- palmente os produzidos pelos estúdios Disney. Mesmo as princesas guerreiras que carregam uma ou outra característica são, ainda, constituídas com os elementos que compõem o "suposto" universo feminino, como a vestimenta, os traços corporais e a própria voz, para desempenhar um papel já esperado. A seguir, a figura da Princesa Caroço.

Figura 2: Princesa Caroço.

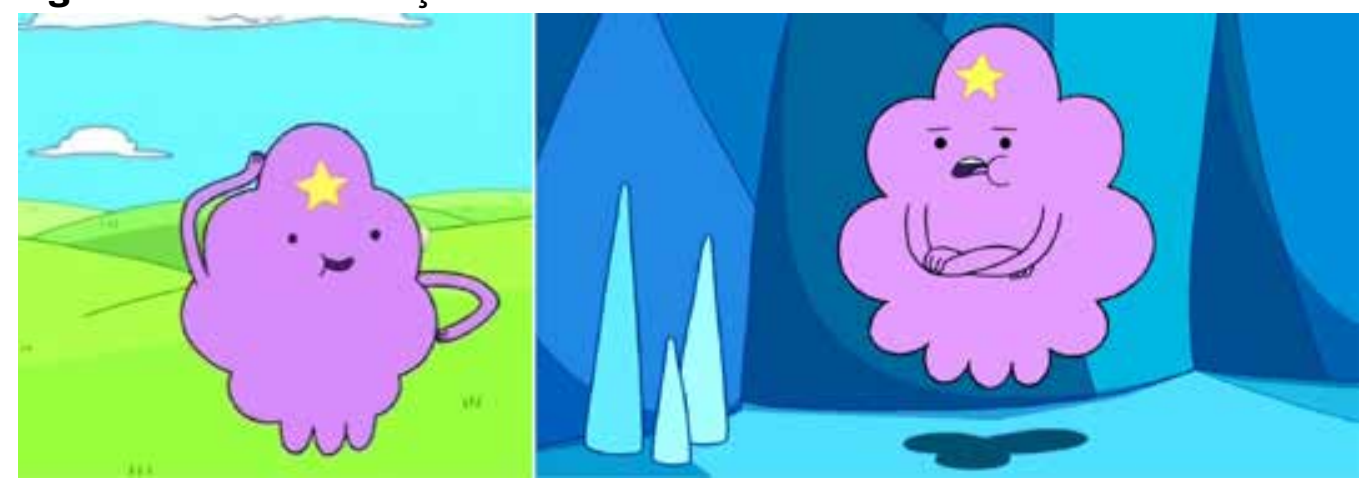

Os "temas legais" a que se refere Jean Grey se relacionariam, também, à existência desta desaglutinação do binarismo que decorre da aparição do rei nos trajes da Princesa Jujuba, no episódio "Mamãe disse", e a exigência que ela/e faz, na forma como quer ser tratado: My Lady. O que para Finn e Jack não é um problema, nem a troca do traje e muito menos a forma de tratamento, tanto no início do episódio, quanto no fim, pois ambos o chamam de "My Lady" e "Princesa da Terra de Ooo".

Figura 3: Cenas do Espisódio “Mamãe disse”, com Finn, Jack e o Rei de Ooo.

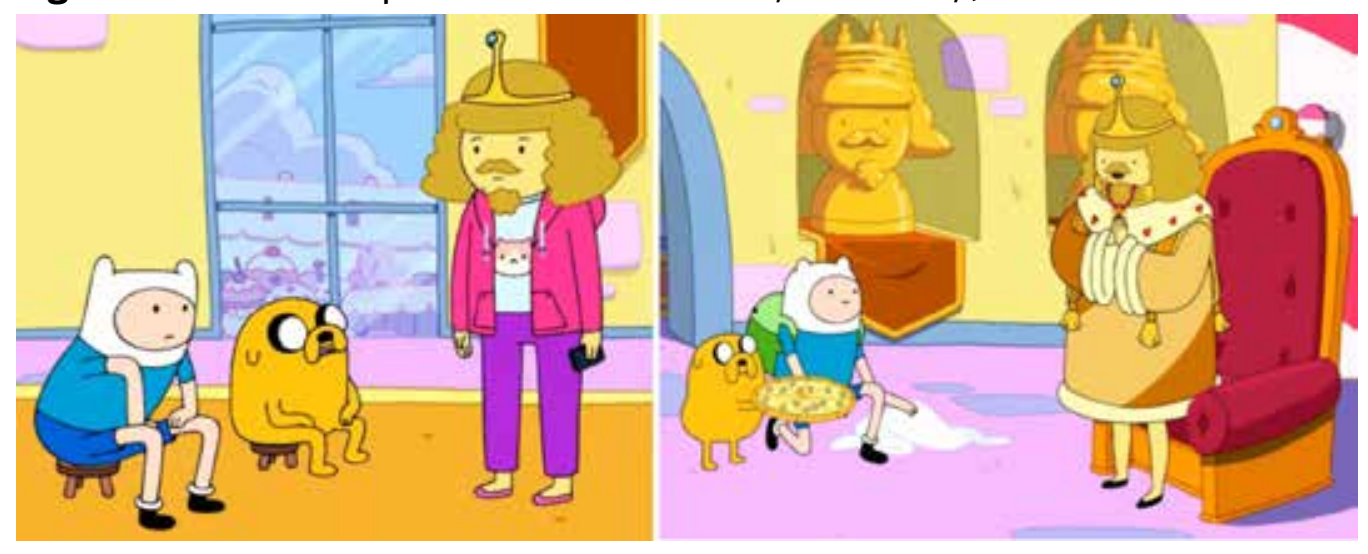

As fissuras estabelecidas nas fronteiras de gênero são provocadas pela atitude do Rei em usar a roupa da princesa e exigir o tratamento no feminino. Estas fissuras desencadeiam algumas ponderações do grupo de exibição sobre os limites entre a identidade de gênero e a estética. Mostram-se favoráveis à transposição da fronteira estabelecida a partir da vestimenta. Esta, agora, parece ser ressignificada, brecha que parece ser lugar de aconchego para as alunas Jean Grey, Vampira e Ororo, enquanto que, para Lince Negra, gera uma relação com a 
sua própria vivência. No trecho a seguir, quando foram indagadas e indagados sobre a aparição do rei em trajes de princesa, as provocações produziram desestabilizações:

Lince Negra: Sei lá, para mim, cada usa o que quer, se veste como quer, faz o que quer.

Jean Grey: Menina liberal. (risos)

Lince Negra: É, minha mãe diz que eu me visto igual a um machinho.

Pesquisador: Por que ela diz isso?

Jean Grey: Somos duas, somos duas.

Lince Negra: Porque eu só uso calça, não gosto de vestido, não gosto de saia.

Ororo: Também não gosto.

Lince Negra: Dá nervoso no coração se tiver que usar vestido ou saia.

Vampira: $O$ bagulho é calça.

Lince Negra: Aí, eu só uso calça, short, minha vida é calça, short e tênis. Não gosto de sapatinho, odeio sapatinho, odeio salto, não sei como a mulher consegue ficar de salto, Jesus do céu! É uma dor, hum, misericórdia!

As falas provocam desestabilização nas meninas, quando se trata dos padrões marcadores da feminilidade das meninas. Ao questionarem os vestidos e saias como vestuário exigido para mulheres, elas colocam o gênero em questão. Além disso, os desenlaces das identidades de gênero não provocaram, automaticamente, um questionamento da orientação sexual, neste episódio, ou seja, o fato do rei aparecer vestido, no início, com os trajes da princesa não fez com que o grupo colocasse em suspeita sua orientação sexual. Pelo contrário, quando indagadas e indagados se o rei seria gay, por estar usando as roupas de princesa, se posicionaram apresentando dois exemplos. 0 primeiro diz respeito a um menino de uma turma que usa salto alto e dos homens heteros, que são dançarinos de Stiletto.12

12 o Stiletto é caracterizado como a dança com salto alto, realizada por divas, em que se mistura jazz, hip hop e música pop. Considerada uma dança sensual, popularizou-se com o desempenho de algumas cantoras, como a estadunidense Beyoncé. É apontada como referência neste estilo Dana Foglia, dançarina do Broadway Dance Center. Disponivel em: <http://
Estas reflexões evidenciam as fragilidades das fronteiras entre o masculino e o feminino, bem como dialogam com possibilidades de ruptura de padrões que servem para identificar gênero e sexualidades.

Tempestade: Também tem a dança que é o Stiletto e têm alguns homens héteros que dançam. Jean Grey: A dança é feita de salto alto, dança de divo.

Tempestade: Sim.

Vampira: Quando passou uma entrevista de um dançarino na televisão, meu pai fez um comentário esquisito. Virei para ele e falei: “Pai, o cara é hétero, mas ele tá usando salto porque é o trabalho dele. Ele é professor de Stiletto, ele usa salto, ele é hétero, ele tem família". Não é só porque o cara usa salto que ele vai ser gay. (risos)

Lince Negra: As pessoas olham para a outra e já descrevem a pessoa a partir da aparência. Se está usando salto, se você colocar uma imagem da pessoa dançando [...] e pedir para descrever eles vão falar que é viado. Só que a pessoa está sofrendo uma, como é que se fala?

Vampira: Uma discriminação?

Lince Negra: Uma discriminação, um preconceito, que não tem nada a ver. Gente! Se a pessoa usa salto, pode ser o trabalho dela, só que tem gente que vê e já aponta, entendeu? Não é o salto ou o brinco ou o vestido que te faz "viado".

O diálogo acima nos permite pensar que as alunas apontam formas divergentes do que prescreve a heterossexualidade padrão. Visibilizam outras formas de pensar o gênero, as sexualidades e suas manifestações mais concretas, indicando que tanto as marcas simbólicas das vestimentas como as performances não evidenciam orientações sexuais rígidas nem definidas. Para Louro (2013, p. 11), "a sexualidade envolve rituais, linguagens, fantasias, representações, símbolos, convenções", configurando "processos culturais e plurais". É por meio desses processos que vamos produzindo e transformando conhecimentos que

www.purepeople.com.br/noticia/beyonce-e-anittasao-fas-do-stiletto-conheca-mais-sobre-a-dancado-salto-alto a28190/1>. Acesso em: 30 mar. 2017. 
não se instauram como prontos, fechados e certos. Assim, as corporalidades vão ganhando sentidos sociais a partir dos modos como percebemos estes corpos. No diálogo, as alunas parecem construir uma nova forma de ver as masculinidades e, portanto, inscritas em identidades múltiplas e provisórias. De acordo com Louro (2013, p. 12), "essas múltiplas e distintas identidades constituem os sujeitos, na medida em que esses são interpelados a partir de diferentes situações, instituições ou agrupamentos sociais". Dessa forma, o reconhecimento de uma identidade não é simples, nem estável. Constituímos identidades diversas, múltiplas, plurais. Estas identidades estão carregadas de provisoriedade, de transitoriedade e de contingência.

$\mathrm{Na}$ tentativa de justificar a fronteira do gênero masculino para o feminino, as alunas argumentam que, por se tratar de um trabalho, há uma permissão da quebra de uma regra de representação da masculinidade: o homem usar salto alto. 0 que não deixa de ser potente, embora a justificativa não questione esta norma por dentro, mas, antes, cria um consentimento temporário que permite ao homem adentrar o "universo feminino", como um nobre que poderia, de certa forma, não sofrer embaraços (BOURDIEU, 2010, p. 75).

Num segundo momento, as meninas parecem absolver o rei de possiveis embaraços quanto a sua performance, transferindo a responsabilidade das classificações para outrem. Na sequência da conversa, Lince Negra afirma que "as pessoas insinuam que ele é gay, as pessoas veem ele como um gay". Em outro momento, as meninas parecem sugerir que, para se atribuir uma orientação sexual ao rei, era preciso que ele tivesse demonstrado algum interesse romântico em alguém, conforme diz Jean Grey: “mas, até agora ele não demonstrou interesse romântico em ninguém, então já não dá para determinar isso. Ele não demonstrou nenhum afeto por qualquer homem, como o Finn, por exemplo".

As meninas parecem colocar o "interesse romântico" como um primeiro marcador pelo qual se pode determinar uma "suposta" identidade e orientação sexual homossexual. Desta forma, a marcação para se determinar heterossexualidade está em constante diálogo e, ao mesmo tempo, em conflito com a marcação da homossexualidade. Para elas, dançar Stiletto e trocar de roupas com uma princesa, por mais que sejam performances que explicitem o não heterossexual, são tomadas como uma diferença que está para além das construções binárias.

Dessa forma, homem que dança com salto alto e rei que se veste com roupas de princesa são casos sintomáticos da fragilidade destas atribuições nas representações, como regimes de verdades para definir gênero e sexualidade (HALL, 2016; LOURO, 2014; 2015; FOUCAULT, 1984). Desestabilizam a noção de identidade no âmbito do jogo político das relações de poder. E anunciam seu caráter flutuante e flexível, ainda que se concretizem nos lugares hierarquicamente preestabelecidos, pois se trata de construções sociais e culturais (SILVA, 2014; WOODWARD, 2014), que decorrem das relações de poder, ou seja, estão ligadas aos modos que definem quem e como podem estabelecê -las. Louro (2013) reforça que nossos corpos se constituem na referência que sustenta a identidade e se espera que eles ditem a identidade sem ambivalências e sem inconstância. No entanto, nossos corpos são significados, ressignificados e alterados pela cultura.

Em relação ao episódio "O que faltava", havia uma aura de euforia em discuti-lo. Neste episódio, há indícios de uma suposta relação amorosa entre a Princesa Jujuba e a Vampira Marceline. 0 momento em que Jack entrega a camisa de rock que julgou pertencer a Marceline, mas que de fato era um presente 
dado à Princesa Jujuba por Marceline, foi tomado pelas meninas com entusiasmo e pareceu ratificar as especulações sobre o casal. Uma camisa que era utilizada pela Princesa
Jujuba como um pijama e que deixa Marceline corada, uma vez que se surpreende, pois havia pensado que Jujuba havia feito pouco caso do presente.

Figura 4 - Espisódio "O que faltava", Princesa Jujuba e Marceline.

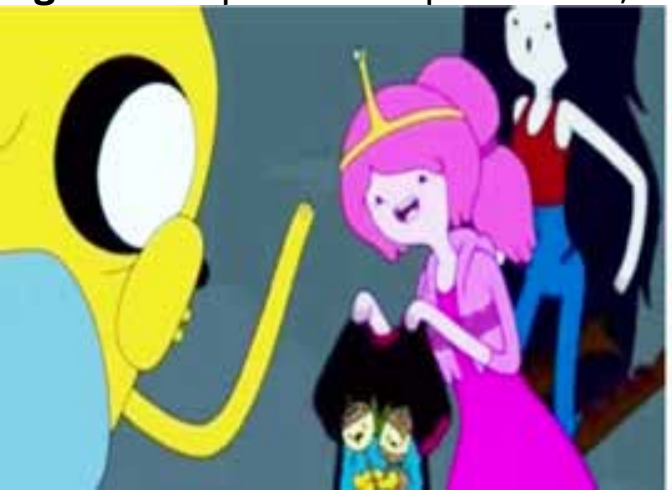

O que faz "A Hora da Aventura" divergir desse modelo tradicional dos desenhos animados e encontrar consonância nas experiências de vida de alunas como Jean Grey e Vampira, meninas que se definiram como lésbicas, nas conversas informais; e Lince Negra, como bissexual, é justamente abordar as temáticas do gênero e da sexualidade, sem cair totalmente naquilo que Giroux (2013) vai chamar de "regimes dominantes de representação". O que dá indícios de minar por dentro estes regimes e ensejar reconhecimentos positivos, não estigmatizados, aparece, nesta conversa, em que a diferença é celebrada como representatividade.

Pesquisador: $\mathrm{E}$ aí galera? E o que podemos falar sobre este episódio?

Vampira: Só aumenta mais o meu Shipp ${ }^{13}$ aqui. Jean Grey: Casalzinho.

Vampira: A Jujuba e a Marceline são um casalzinho.

Pesquisador: Como assim? [...]

Jean Grey: É que as duas são vistas como um casal romântico.

Pesquisador: Mas, quem disse isso?

Jean Grey: Saiu na internet e o autor confirmou.

Pesquisador: Como ele confirmou isso?

Jean Grey: Através de uma mensagem. Ele disse para a dubladora da Marceline (original em

13 Shipp é o termo utilizado entre elas para significar um casal que tem o apoio do grupo.

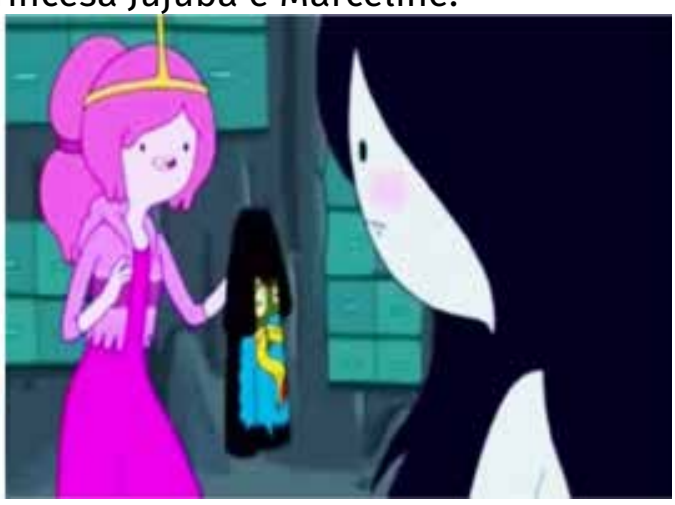

inglês) e ela transmitiu ao público numa conferência.

Pesquisador: Que as duas são namoradas?

Jean Grey: Já foram.

Pesquisador: Ah, já foram?

Jean Grey: E a gente fica esperando que elas voltem a ser, mas...

Pesquisador: Por que vocês ficam esperando? Jean Grey e Vampira: Fofas (falaram ao mesmo tempo e com muitos risos).

Lince Negra: Gente, calma.

Pesquisador: Que elas são fofas, o que seria isso?

Tempestade: Um casal diferente.

Vampira: É porque é um casal diferente também, são dois mundos diferentes, os opostos se atraem.

Um casal diferente, em que a Princesa Jujuba representa uma vida, cujo feminino parece estar vinculado aos modelos dominantes de feminilidade, enquanto a outra aos modelos transgressores, conforme se depreende da descrição de ambas, pelas alunas.

Vampira: Assim, uma é toda fofinha. Toda doce. Ororo: Meiga.

Jean Grey: A Princesa Jujuba é muito certinha. Ororo: Chatinha.

Vampira: A outra é mais roqueirona, vida louca, gosta de rock e tal. É bem legal o fato delas se gostarem, mesmo sendo muito diferentes uma da outra. 
Diferente e fora das convenções sociais que estabelecem um ponto de identificação entre o que se pode chamar vida real e virtual (MARTÍN-BARBERO, 1997), entre o mundo ordinário das imposições e da manutenção de uma perspectiva única e a pluralidade que brota nas ramificações do cotidiano, que não é linear, mas mutável e fluido. No trecho a seguir, quando o pesquisador as provoca, questionando se não se trataria apenas de uma amizade entre as duas, elas são categóricas nas afirmações:

Lince Negra: Não.

Jean Grey: Mesmo que não fossem um casal, seriam em algum momento.

Vampira: É uma amizade bonita.

Jean Grey: Amizade interessante!

Pesquisador: Por que não seriam apenas amigas?

Lince Negra: Porque quando a gente bate o olho em duas pessoas com esta intimidade como a delas, a gente já identifica que são um casal.

Jean Grey: Mesmo que não seja, a gente sabe que vai virar, no fim vai virar. Guarde minhas palavras, mulheres! (muitos risos)

O fato de serem amigas ou um casal torna-se irrelevante, pois, de algum modo, os comentários na internet, as insinuações que são feitas sobre este relacionamento, assim como vê-lo e poder especular a respeito, trazem consigo evidências de que outras abordagens, além de necessárias, são possiveis e perceptiveis por parte das alunas. Isso parece criar uma possibilidade de identificação entre as meninas e as personagens, cuja potencialidade, neste episódio, encontra-se na sugestão da existência de representações de identidades de gênero até então excluídas dos desenhos animados.

Estendemos um pouco mais a problematização acerca do par romântico lésbico, procurando identificar como chegaram a esta afirmação e que elementos poderiam ser acionados para sustentar tal posição. Neste trecho, elas apontam o seguinte:
Pesquisador: Vocês conseguem ver isto no desenho ou é só porque o autor disse?

Lince Negra: Tudo, assim, nos gestos.

Jean Grey: Na verdade, têm cenas que elas mostram muita intimidade.

Vampira: Também têm várias fotos na internet. Jean Grey: Durante outros episódios, há cenas que elas demonstram muita intimidade. Jogam indícios sobre o passado delas, de cada uma, delas duas juntas e tudo mais.

Pesquisador: Intimidade, em que sentido? Que intimidade é essa?

Jean Grey: Troca de roupas. (muitos risos)

As alunas parecem resgatar outros momentos da narrativa que, de alguma forma, explicam o fato de não estarem juntas. Especulam que o conflito entre elas se dá pelos estilos diferenciados de cada personagem. Desta forma, há uma classificação das duas, a partir das atribuições que uma menina pode ter ou não e que a ajudaria, de certa forma, a se relacionar e manter este relacionamento. Enquanto descrevem como a Princesa Jujuba está atrelada ao Reino Doce e isto a impede de viver livremente, Marceline é associada à ideia de um espírito livre, que não se prende a nada, nem a ninguém, o que seria um elemento que dificultaria um relacionamento.

Jean Grey: Assim, analisando como a possibilidade delas se gostarem e não poderem ter sido um casal no passado, eu acho que posso dizer que é porque a Jujuba, sendo a princesa, tinha deveres com o reino.

Ororo: Ela tinha que exercer o papel dela.

Jean Grey: Não é questão dela não namorar a Marceline, mas a Marceline sempre demonstrou ser uma pessoa de espírito muito livre.

Jean Grey: Ela é a Rainha Vampira, a roqueira das trevas.

Vampira: Solidão, solidão. (risos)

Quando perguntadas se uma princesa necessariamente teria estes atributos e não poderia ter o "espírito livre", entram em mais uma discussão e acabam por reconhecer que as imposições são colocadas, são políticas e 
que agem conforme determinados modos de ser. Não é uma escolha romantizada como os desenhos da Disney sobres as princesas fazem crer, que, supostamente, escolhem seu destino. Esta definição de "espirito muito livre" parece acompanhar as meninas que se definiram como lésbicas e bissexuais, as alunas Lince Negra, Jean Grey e Vampira, uma vez que afirmaram se parecer mais com a Marceline pelo "fato de ela ter tipo os dois lados, tipo meio roqueirona, uma loucona, mas na hora ela expressou os sentimentos dela, mas assim quando ela viu que estava expressando demais ela parou e voltou a ser friazona". Por outro lado, as alunas Tempestade e Ororo, que se definiram como heterossexuais, afirmaram se parecer mais com a Princesa Jujuba

Parecer-se com a Vampira Marceline, a quem sugerem perceber como subversiva, evidencia que estas identificações, de certo modo, são possiveis como resistências. Cada uma acaba, em alguma medida, desenvolvendo estratégias para visibilizar sua orientação sexual e sua identidade de gênero, nos espaços mais diversos, inclusive no ambiente familiar. A partir da discussão do episódio, Lince Negra narrou o momento em que contou para a mãe que, além de namorar meninos, também namorava meninas.

No ano passado, eu pegava muita mulher. Pegava mais mulher do que eu pego homem, hoje em dia, entendeu? Um dia, eu estava quase namorando uma garota e resolvi contar para minha mãe. Não foi fácil. Eu estava no maior cagaço. ${ }^{14}$ Pô, e eu gostava pra caramba da garota. Disse para ela: "mãe, estou quase namorando uma garota. Enfim, sou lésbica, tá?" Ela ficou paralisada, olhando para minha cara pelo menos por uns 5 minutos. De repente, a primeira frase: "Você tá maluca? Você não é normal não, garota". Falei assim: "Ué, hoje em dia é uma coisa normal". Ela virou e me disse: "Seu pai vai me matar, cara. Sua avó vai me matar. Você sabe muito bem porque sua avó vai me matar. Ela é

14 Gíria que indica medo, temor. da igreja e você sabe como é esse povo". Depois disso, o clima mudou totalmente lá em casa. Meu pai não ficou sabendo, nem minha vó. Mas, agora, o clima já está mais normal. Eles aceitam que eu seja bissexual, mas não falamos muito no assunto. Até apresentei a menina para minha mãe. Tá de boas! (Lince Negra)

O "suposto" relacionamento de Jujuba e Marceline vem corroborar a representação positiva de uma relação homoafetiva que é vigiada e silenciada, na maioria dos desenhos animados. Representação esta que parece não encontrar correspondente, quando se trata do relacionamento entre dois meninos. Como apontado por Vampira e Jean Grey, entre dois homens, prevalece o "princípio antagônico da identidade masculina e da identidade feminina", que estão atreladas à "naturalização de uma ética" (BOURDIEU, 2010, p. 38). O policiamento incisivo sobre a mulher torna-se ameno, quando esta passa de sujeito a objeto de prazer, enquanto sobre os homens qualquer traço que torne manifesto uma feminização é reprovável tanto quanto vigiado. Mecanismos de vigilância que são utilizados para objetificar a mulher e que se encontram na estrutura social, apontada por Lévi-Strauss (1982) e Gayle Rubin (1993), como os modos que as tornam uma parte daquilo que pode ser negociado, que as tomam como mercadoria a ser negociada.

\section{O que fica desta aventura?}

Como espaço potente para aprofundar as discussões de gênero e seus desdobramentos, a escola configura-se como um lugar importante para o combate à discriminação e ao preconceito. De acordo com Miskolci (2014), a escola, seu currículo e as práticas nela realizadas podem "quebrar o silêncio" sobre relações de gênero e sexualidades, propiciando um lugar agregador das diferenças. A partir do uso de imagens diversas (cinema, desenho animado, 
vídeos, fotografias etc.), professores e professoras podem abordar aspectos inerentes à sexualidade e às questões de gênero, a partir de situações do cotidiano, de assuntos expostos na mídia, da discussão de um filme ou da leitura de um romance, de uma matéria jornalística, de uma campanha publicitária.

As práticas pedagógicas que tratam da diversidade sexual podem ser meios potentes para coibir preconceitos e discriminações. Caso um menino ou menina rompa com uma convenção de gênero e venha a sofrer xingamentos e humilhações dos colegas, o professor ou a professora deve se manifestar de forma a restabelecer o respeito ao/à “insultado/a”. Tal atitude contribuirá para que todos se confrontem com uma forma diferente de agir e pensar.

Nesta pesquisa, assim que finalizamos a sessão de exibição, as discussões e desligamos o gravador, Lince Negra respirou fundo e pronunciou em alto e bom som: "como eu queria mostrar esta gravação para o meu pai, assim do jeitinho que está aqui". Esta manifestação parecer sugerir que o espaço propiciado pela pesquisa, na escola, foi promissor, no sentido do acolhimento de formas outras de manifestação das identidades de gênero e sexuais. A fala de Lince Negra traz o indicativo, também, de que ainda é necessário avançar muito nesta discussão.

A apresentação do relacionamento entre as duas personagens Marceline e a Princesa Jujuba, a troca de roupa do Rei, além de muitos outros elementos que não foram abordados aqui, trazem à superficie a necessidade, premente, de tratar das temáticas de gênero e sexualidade no ambiente escolar, fonte de ataques conservadores cotidianos. "A Hora da Aventura" traz uma potência que contribui para fomentar o debate em diversos lugares, no que tange às discussões sobre representação e identidades, em que comportamentos e corpos historicamente atribuídos a caracte- rísticas femininas ou masculinas estão, constantemente, fissurando as fronteiras, desconstruindo-as, ressignificando-as.

Os modelos que vigoram na maioria dos desenhos animados, ainda que na sua maioria, dentro de uma lógica binária, são, em "A Hora da Aventura", no mínimo, alargados. As noções de feminino e masculino que o desenho trabatha se inscrevem como mais flexiveis e fluidas e rompem, de certa forma, com o silenciamentos que se tem imposto às expressões não binárias e dissidentes de gênero e sexualidade.

Vampira termina da seguinte forma: "estou com medo desta gravação". Sua fala nos obriga a pensar e produzir outras vias para que as singularidades sejam contempladas e tomadas em suas diferenças, como perfazendo um caminho que começa sempre e nunca acaba (GALLO, 2014). Faz-nos pensar que, ao narrarmos histórias diversas, também estamos nos narrando e, portanto, nos modificando. Podese sustentar que "A Hora da Aventura" abordou e aborda as temáticas de gênero com desenlaces tão sutis que está a desatar este nó, a partir de representações ousadas de identidades de gênero e orientações sexuais consideradas marginais.

Por fim, compreendemos que as questões relacionadas a gênero e a diversidade sexual tornam-se fulcrais na atualidade, considerando-se todo o cenário complexo, múltiplo e em constante disputa, por visões de mundo, por ideias, por comportamentos e por valores, além de serem parte constituinte das nossas identidades. Professores e professoras, ao contrário do que pensam alguns movimentos conservadores, devem enfrentar tal desafio, formando-se e inserindo/aprofundando a discussão em suas aulas, em suas práticas. Não devem deixar que a "mordaça” seja instrumento para calar suas vozes e suas lutas em prol de uma educação inclusiva e verdadeiramente democrática. 


\section{Referências}

BHABHA, Homi K. O local da cultura. Tradução de Myrian Avila; Eliane Lourenço de Lima Reis; Gláucia Renate Gonçalves. Belo Horizonte: Editora UFMG, 1998.

BOURDIEU, Pierre. A dominação masculina. Tradução de Maria Helena Kühner. 9. ed. Rio de Janeiro: Bertrand Brasil, 2010.

BRAH, Avtar. Diferença, diversidade, diferenciação. Cadernos Pagu, n. 26, p. 329-376, 2006. Disponível em: <http://www.scielo.br/pdf/cpa/n26/30396. pdf>. Acesso em: 13 mai. 2016.

BRASIL. Gênero e diversidade sexual na escola: reconhecer diferenças e superar preconceitos. Cadernos SECAD 4, MEC: Brasília, 2007.

BRASIL. Lei no 13.005 de 25 de junho de 2014. Disponivel em: <http://www.planalto.gov.br/CCIVIL 03/ Ato2011-2014/2014/Lei/L13005.htm>. Acesso em: 05 jul. 2017.

BRASIL. Projeto de Lei no 867, de 2015. Câmara dos Deputados: Brasília, 2015. Disponível em: <http:// camara.gov.br/proposicoesWeb/fichadetramitacao?idProposicao=1050668>. Acesso em: 05 jul. 2017.

BUTLER, Judith. Problemas de gênero: feminismo e subversão da identidade. Tradução de Renato Aguiar. 8. ed. Rio de Janeiro: Civilização Brasileira, 2015. (Coleção Sujeito e História).

FOUCAULT, Michel. Microfísica do poder. Tradução de Roberto Machado. Rio de Janeiro: Graal, 1984.

GALLO, Silvio. Diferença, multiplicidade, transversalidade: para além da lógica identitária da diversidade. In: RODRIGUES, Alexsandro; DALLAICULA, Catarina; FERREIRA, Sérgio Rodrigo da S. (Orgs.). Transposições: lugares e fronteiras em sexualidade e educação. Espírito Santo: EDUFES, 2014. p. 187-202. GIROUX, Henry A. A disneyzação da cultura infantil. In: SILVA, Tomaz Tadeu da.; MOREIRA, Antonio Flávio. (Orgs.). Territórios contestados: o currículo e os novos mapas políticos e culturais. Petrópolis, RJ: Vozes, 1995. p. 49-81.

; MCLAREN, Peter L. Por uma pedagogia crítica da representação. In: SILVA, Tomaz Tadeu da.;
MOREIRA, Antonio Flávio. (Orgs.). Territórios contestados: o currículo e os novos mapas políticos e culturais. Petrópolis, RJ: Vozes, 1995. p. 144-158.

Memória e pedagogia no maravilhoso mundo da Disney. In: SILVA, Tomaz Tadeu da. (Org.). Alienigenas na sala de aula. 11. ed. Petrópolis, RJ: Vozes, 2013. p. 129-154. (Coleção Estudos Culturais).

HALL, Stuart. Cultura e representação. Rio de Janeiro: Ed. PUC-Rio; Apicuri, 2016.

LÉVI-STRAUSS, Claude. As estruturas elementares do parentesco. Petrópolis, RJ: Vozes: 1982.

LOURO, Guacira Lopes; FELIPE, Jane; GOELLNER, Silvana Vilondre. (Orgs.). Corpo, gênero e sexualidade: um debate contemporâneo na educação. 9. ed. Petrópolis, RJ: Vozes, 2013.

Gênero, sexualidade e educação: uma perspectiva pós-estruturalista, 16. ed. Petrópolis, RJ: Vozes, 2014.

MARTÍN-BARBERO, Jesús. Dos meios às mediações: comunicação, cultura e hegemonia. Rio de Janeiro: Editora UFRJ, 1997.

MISKOLCl, Richard. (Org.). Marcas da diferença no ensino escolar. São Carlos: EdUFSCar, 2014.

RAMOS, Rebecca Costa. FERNANDES, Kamila Bossato. Análise do desenho animado "Hora da Aventura": as diferentes leituras da mesma mensagem. In: CONGRESSO BRASILEIRO DE CIÊNCIAS DA COMUNICAÇÃO, 39., 2016, São Paulo. Anais... São Paulo: Intercom Sociedade Brasileira de Estudos Interdisciplinares da Comunicação, 2016. p. 01- 12.

RUBIN, Gayle. 0 tráfico de mulheres: notas sobre a "economia política" do sexo. Recife: SOS Corpo, 1993. Disponivel em: <https://repositorio.ufsc.br/ xmlui/handle/123456789/1919?show=full>. Acesso em: 19 dez. 2016.

SILVA, Tomaz Tadeu da. A produção social da identidade e da diferença. In. SILVA, Tomaz Tadeu da. (Org.). Identidade e diferença: a perspectiva dos estudos culturais. 15. ed. Petrópolis, RJ: Vozes, 2014. p. 73-102. 
SILVA, Bruna Tairine. A representação social da infância veiculada no desenho animado Hora da Aventura. 2016. 135 f. Dissertação (Mestrado em Educação) -Programa de Pós-Graduação em Educação da Faculdade de Ciências e Tecnologia, UNESP/ Campus de Presidente Prudente, Presidente Prudente, 2016. CAPES 33004129044P6, 2016.
WOODWARD, Kathrny. Identidade e diferença: uma introdução teórica e conceitual. In: SILVA, Tomaz Tadeu da. (Org.). Identidade e diferença: a perspectiva dos estudos culturais. 15. ed. Petrópolis, RJ: Vozes, 2014. p. 7-72.

Recebido em: 10.08.2017 Aprovado em: 03.11.2017

André Luiz Bernardo Storino é Professor da Secretaria de Estado de Educação do Rio de Janeiro. Mestre em Educação, Cultura e Comunicação em Periferias Urbanas - FEBF/UERJ (Faculdade de Educação da Baixada Fluminense - Universidade do Estado do Rio de Janeiro). e-mail: albstorino@yahoo.com.br

Rua Edir Barbosa, s/n - Xerém - Duque de Caxias - RJ. (21) 981605968

Ivam Amaro é Doutor em Educação (UNICAMP). Professor Adjunto do Departamento de Formação de Professores da FEBF/UERJ (Faculdade de Educação da Baixada Fluminense - Universidade do Estado do Rio de Janeiro). Professor do Programa de Pós-Graduação em Educação, Cultura e Comunicação em Periferias Urbanas PPGECC/UERJ. e-mail: ivanamaro.uerj@gmail.com

Rua General Manoel Rabelo S/N, Vila São Luís - Duque de Caxias - RJ - (21) 36573021. 